\title{
Medication in nursing homes in Alsace: a preferential list of drugs obtained by consensus
}

\author{
Sophia Hannou ${ }^{1,2}$, Amélie Rousseau ${ }^{1}$, Marie-Christine Rybarczyk-Vigouret ${ }^{1}$ and Bruno Michel ${ }^{1,3^{*}}$
}

\begin{abstract}
In order to improve patient care, OMEDIT (Observatory of drugs, medical devices and therapeutic innovation) Alsace, conducted a study to develop a Preferential list of Drugs adapted to the Elderly (PDE list) in nursing homes. The study conducted from December 2011 to June 2012 was organized in 4 phases: 1) creation of a preliminary list of drugs from those currently used in nursing homes in Alsace, 2) application of a two-round Delphi process to evaluate the preliminary list involving mobilization of experts from different backgrounds (geriatricians, general practitioners, pharmacists ...), 3) identification of molecules considered in literature as potentially inappropriate, 4) generation of a final PDE list, including information concerning proper use of drugs for prescription and administration. 53 experts participated in the study. In the first round, 338 drugs were on the preliminary list, 246 were considered as appropriate by experts and 28 as inappropriate. 64 drugs without consensus were submitted to a second round. 32 of them were considered as inappropriate and 32 others remained on the list with no consensus. These last 32 were evaluated by OMEDIT and 3 were considered as appropriate drugs for the elderly. Totally, 252 drugs constitute the final PDE list from our study. The PDE list constitutes a new guide for optimization of both prescription and administration of drugs in nursing homes and could help reduce misuses and poly-medication, which are constant preoccupations to avoid adverse drug reactions in elderly.

\section{Key points:}

- The study was carried out with the aim to create a Preferential list of Drugs adapted to the Elderly (PDE list) in nursing homes using a modified Delphi method.

- The PDE list constitutes a new guideline to harmonize practices in nursing homes and to help physicians and nurses to achieve best possible care management.
\end{abstract}

Keywords: Appropriate drugs; Elderly; Delphi method; Medication; Nursing home; Improving patient care; Optimizing prescription

\section{Introduction}

The European population is living longer than before and the percentage of the elderly in society is a significant demographic change, and as a consequence, the part of this population going to nursing homes is growing. The health status of these frail and/or dependent patients with various pathologies often requires the use of several medications. In this regard, a number of studies have shown that poly-medication, defined as medication with at least 5 to 8 drugs, is common in the elderly with the highest

\footnotetext{
* Correspondence: bruno.michel@chru-strasbourg.fr

'OMEDIT d'Alsace, Cité administrative Gaujot, 14, rue du Maréchal-Juin, F-67084 Strasbourg, France

${ }^{3}$ Service de Pharmacie, Hôpitaux Universitaires de Strasbourg, Université de Strasbourg, Faculté de Pharmacie, Laboratoire HuManiS (EA 7308), 1, avenue Molière, BP 83 049, Strasbourg, Cedex F-67098, France

Full list of author information is available at the end of the article
}

number of drugs taken by those residing in nursing homes (Maher et al. 2014). With the use of multiple medications, an increased risk for negative health outcomes has been described (Maher et al. 2014).

Reducing overuse of drugs in nursing homes, especially to prevent adverse drug reactions (ADRs), is a major health concern and constitutes a challenge for every care giver, even for the most experienced clinicians (Petrovic et al. 2012). In the elderly, the risk of ADRs is positively correlated to the number of drugs used. As an illustration, elderly patients taking 2 drugs face a $13 \%$ risk of adverse drug-drug interactions, and this rises to $38 \%$ for 4 drugs and to $82 \%$ if 7 or more drugs are given simultaneously (Leendertse et al. 2008; Beijer \& de Blaey 2002). The ADRs, in the elderly, often lead to hospitalization and increased expenditure for medical care

\section{实}


(Chen et al. 2014). According to Beijer et al., the average rate of ADR-related hospital admissions is $16.6 \%$ in older patients, compared to $4.1 \%$ in younger patients (Beijer \& de Blaey 2002).

Besides overuse, other considerations must be taken into account to render medications and health conditions secure in the elderly: misuse or under-use of drugs, respect of dosage, appropriate pharmaceutical form in case of deglutition problems. Other factors to be considered are impairment renal or hepatic function and the clinical characteristics of the patient such as alteration in cognitive function, urinary incontinence (Topinkova et al. 2012).

Physicians who are working in nursing homes are usually not geriatricians. Their workload mostly does not allow time for in-depth reviews of literature, which is currently starting to be rich in drug- safety specific reports and lists of potentially inappropriate medication (PIM) for the elderly. Considering the given situation, the idea of guiding the prescription to treat the main pathologies encountered towards drugs belonging to an arsenal validated by a panel of recognized experts was attractive.

This present study was carried out with the aim to create a preferential list of Drugs adapted to the Elderly (PDE list) in nursing homes using a modified Delphi method. This PDE list was based on personal experience/ opinion of 53 experts and available evidence.

The final goal was to provide a support document to help health-care professionals (mainly general practitioners, but also nurses and pharmacists) in nursing homes to set their own guidelines for one main objective: simplifying prescription and administration in order to improve the management of drug therapy in the elderly.

\section{Methods}

This study was carried out from December 2011 to June 2012 and was conducted by OMEDIT (Observatory of drugs, medical devices and therapeutic innovation) Alsace in France. Alsace is a region in France with 1.8 million inhabitants.

The literature contains many different age thresholds for the definition of the elderly. The threshold of 65 years with poly-pathologies or 75 years or more were the cut-offs retained in this study [ANSM (ex Afssaps) 2005].

\section{Study design}

The data was collected in 4 phases (Figure 1).

1) Creation of a preliminary list of drugs based on formularies used in daily practices in nursing homes in Alsace.

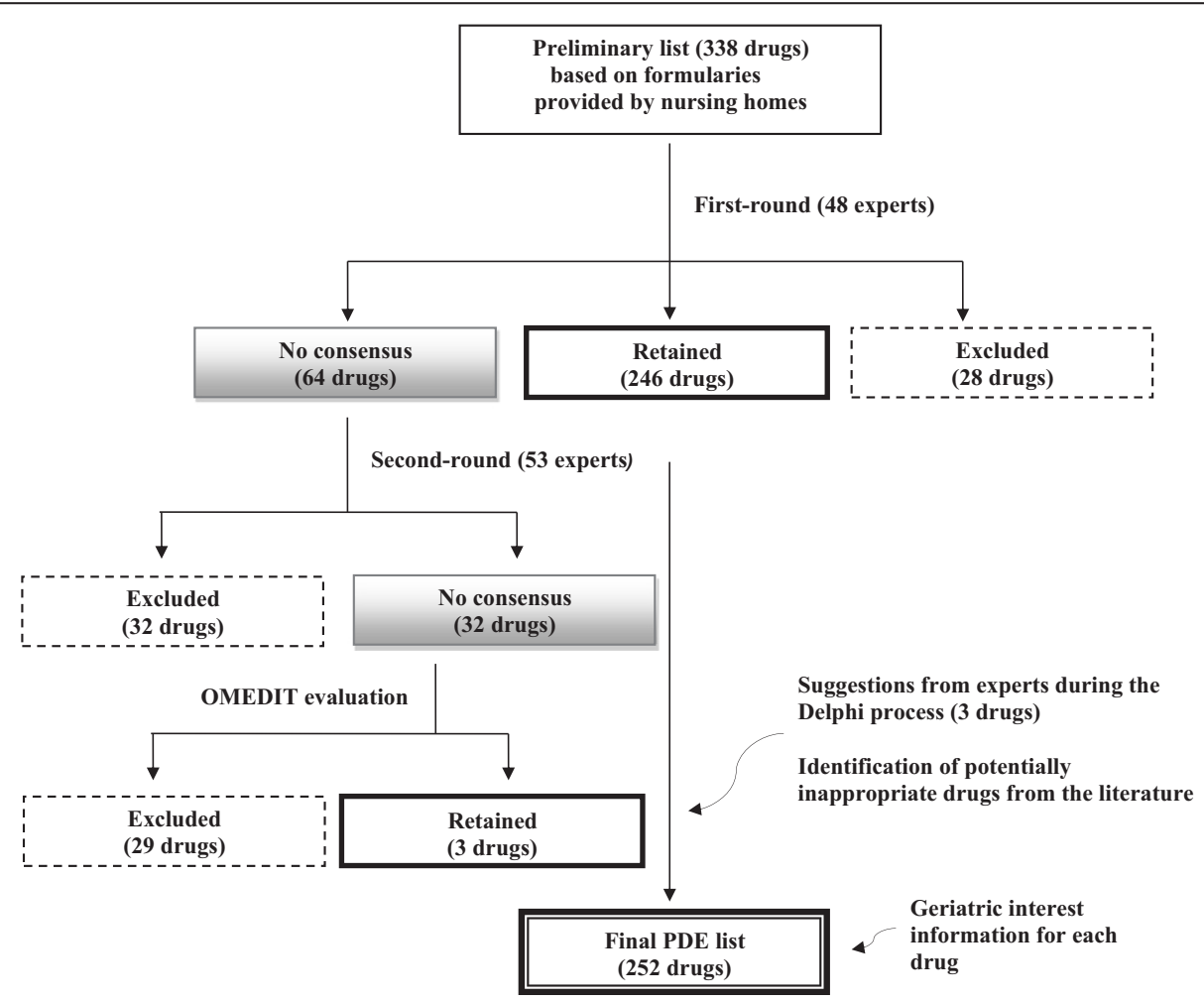

Figure 1 Presentation of the Delphi process used to generate the preferential list of drugs adapted to the elderly (PDE list). 
2) Application of a two-round Delphi process to evaluate the preliminary list in order to lead to build a PDE list. This step included:

a) recruitment of experts,

b) creation of a first-round of a survey and subsequently sending e-mails to the experts,

c) creation of the second-round of the survey based on results from the first round and receiving feedback from the panel of experts.

3) Identification of molecules considered in literature as potentially inappropriate in the preliminary list and in the PDE list obtained from Delphi process.

4) Generation of the final PDE list containing appropriate drugs for the elderly based on the experts' opinion and combined also with practical information for the proper use of drugs, in terms of prescription and administration.

\subsection{Creation of a preliminary list of drugs commonly used in nursing homes}

An inventory of the available drug formularies used in nursing homes in Alsace was carried out in December 2011. Drugs present in more than $20 \%$ of the formularies analyzed were selected to be part of the preliminary list of the study. Specific treatments such as antineoplastic drugs were excluded from the study.

\subsection{Application of the Delphi method}

The Delphi method, developed by the Rand Corporation in the 1950s, is a research method allowing a consensus opinion to be reached among experts through an iterative and anonymous process known as rounds (Dalkey 1969). The method uses surveys in order to collect information. Two rounds were carried out in our study. The responses from the first round were collected and analyzed; a revised survey was then submitted to the experts to initiate the second round.

\section{Experts: panel selection}

After consulting several healthcare professionals and scientific societies specialized in the field, a panel of potential members with recognized expertise was identified and invited to participate in this study. Care was taken to select experts from Alsace $(44=$ experts) but also from other parts of France ( $n=4$ experts) and from neighboring countries ( $\mathrm{n}=5$ experts). These experts represented 6 different specialties [geriatric medicine $(n=22)$, clinical pharmacology $(n=2)$, general practice in nursing homes (10), pharmacovigilance $(\mathrm{n}=2)$ and pharmacy $(\mathrm{n}=17$ experts, 7 community pharmacists practicing in nursing homes and 10 hospital pharmacists].

\section{Data collection and analysis}

First-round The preliminary list was used to formulate the first round of the survey which was then sent by e-mail to the experts. They rated each drug on a five-point Likert scale, which ranges from a score of 1 (drugs that can be considered as appropriate for the elderly in nursing homes) to 5 (drugs that can definitely be considered as inappropriate in nursing homes) (Matell \& Jacoby 1971). An appropriate drug was defined as an indispensable drug with a clear-cut benefit in terms of efficacy/safety ratio or a drug with obvious efficacy.

A score of 3 was considered as neutral (undecided). After the first round, the mean Likert score and the corresponding 95\% confidence interval (CI) were determined for each drug. Drugs, for which the upper bound of the $95 \%$ CI was less than 3.0, were classed as appropriate, while drugs, for which the lower bound of the $95 \%$ CI was greater than 3.0, were classed as inappropriate drugs for elderly persons. Only the drugs whose $95 \%$ CI was on both sides of 3.0, were evaluated further by the experts, in the second round of questioning. During the first-round, experts were also invited to add comments, to suggest safer or more appropriate alternative therapeutics.

Second-round The second-round of the survey included drugs that didn't reach consensus from round-one with the results of their scores and any statements added by the experts. The data were presented anonymously, enabling the participants to reconsider their previous responses. The answers provided by the experts in the second round were evaluated by the same procedure described above.

\subsection{Potentially inappropriate medications in the elderly}

Three lists of PIM were used to identify drugs categorized as inappropriate from the preliminary and the PDE lists (The American Geriatrics Society 2012 Beers Criteria Update Expert P 2012; Holt et al. 2010; Laroche et al. 2007). We had access to two European lists (one from Germany and one from France) and one list from the American geriatrics society. Although it was not specifically developed for European countries, the list from the United States of America (USA) has already been successfully used to detect PIM in European countries and it has been recently updated (Laroche et al. 2007).

\subsection{Generation of the final PDE list}

The final PDE list was established on the basis of two rounds of the Delphi process. Drugs considered as appropriate in nursing homes by experts but qualified as inappropriate by the literature have been nevertheless retained in the final PDE list. Information concerning the proper use of drugs was added for each drug in the list. 
Concerning this latter point, the data was taken from different sources: European Medicines Agency (EMA), French national agency of drug security (ANSM, Agence Nationale de Sécurité du Médicaments et des produits de santé), French database Thériaque (2014), OMEDIT Normandy (2014) and pharmaceutical companies.

\subsection{Statistical analysis}

Statistical calculations were performed with the SAS program, version 9.1 (SAS Institute Inc Cary, North Carolina, USA).

\section{Results}

Figure 1 summarizes the process used to generate the PDE list.

\subsection{Creation of a preliminary list of drugs used in nursing homes}

One hundred and five nursing homes of Alsace were asked whether they had a formulary of drugs in their facility. Only 23 nursing homes had formularies, of which 20 provided a copy of their document. After reviewing the 20 formularies, we found that they actually corresponded to 15 different lists of drugs. Indeed, in some cases, several nursing homes shared the same formulary. Of the 15 drug formularies, 11 were finally used for the design of the preliminary list. Three formularies were excluded because they were consumer reports without any indications to ensure the proper use of medications and one corresponded to a list of medications which had to be avoided in the elderly.

Drugs present in more than $20 \%$ of the 11 analyzed formularies were then chosen to be part of the preliminary list of our study. Three hundred and thirty eight drugs of the 591 on the lists were thus selected and the preliminary list of drugs was constituted. Table 1 shows the distribution of the 338 molecules of this list according to the ATC classification (Anatomic, Therapeutic and Chemical classification).

\subsection{Application of the Delphi method}

Contacts were established with 50 experts, of whom 48 agreed to participate in the project. The 48 experts completed all rounds of the survey (from February to April 2012). Five additional experts, who were subsequently included by personal communication, then joined the study during the second-round. Finally, the panel of experts was composed of physicians, representing two-thirds of the panel and pharmacists the remaining one-third.

- Based on the results from the first round which evaluated 338 drugs: 246 molecules of the preliminary list were judged to be appropriate for the elderly, 28 drugs were excluded and a consensus
Table 1 Distribution of drugs in the preliminary list according to the ATC* classification

\begin{tabular}{ll}
\hline ATC classification system & Number of drugs \\
\hline A. Alimentary tract and metabolism & 54 \\
B. Blood and blood forming organs & 15 \\
C. Cardiovascular system & 59 \\
D. Dermatologicals & 26 \\
G. Genito urinary system and sex hormones & 12 \\
H. Systemic hormonal preparations & 9 \\
J. Anti-infective for systemic use & 29 \\
L. Antineoplastics and immunomodulating & 5 \\
agents & \\
M. Musculo-skeletal system & 20 \\
N. Nervous system & 74 \\
P. Antiparasitic products, insecticides and & 0 \\
repellents & \\
R. Respiratory system & 22 \\
S. Sensory organs & 13 \\
\hline
\end{tabular}

*ATC: Anatomic, Therapeutic and Chemical classification.

could not be reached for 64 other drugs. Thus, a further evaluation was needed for these last 64 drugs.

- After the second round: 32 drugs were definitely considered as inappropriate for the elderly. For the last 32 drugs, no consensus was obtained (see Table 2). OMEDIT, identified as a group of experts, evaluated these latter 32 drugs.

- OMEDIT evaluation: 29 of the 32 drugs were excluded by OMEDIT Alsace, considering the existence of therapeutic alternatives validated by experts during the first round; the remaining 3 drugs [ibuprofen, diclofenac and tramadol] were on the other hand retained in the list.

During the Delphi process, the experts also suggested new drugs as possible appropriate medications. Among proposals made by the experts, 3 suggestions were retained by OMEDIT Alsace (an antiseptic mouthwash containing chlorhexidine and chlorobutanol, heparin calcium which is suitable for people with impaired renal function and a skin antiseptic containing chlorhexidine). Thus, the Delphi process finally identified 252 drugs. These constitute the proposed PDE list presented in the article.

\subsection{Potentially inappropriate medications in the elderly}

Of the 338 starting molecules (preliminary list of the study) and the 252 drugs of the PDE list, 68 (20\%) and $30(12 \%)$ were respectively considered as potentially inappropriate in the elderly according to the 3 PIM lists mentioned in the methods (The American Geriatrics Society 2012 Beers Criteria Update Expert P 2012; Holt et al. 2010; Laroche et al. 2007). Table 3 shows the 
Table 2 Drugs for which the experts did not reach a clear decision after the 2-round Delphi process

\begin{tabular}{|c|c|}
\hline ATC* classification system & $\begin{array}{l}\text { Drug evaluation on the 5-point } \\
\text { Likert scale mean, and } 95 \% \\
\text { confidence interval }\end{array}$ \\
\hline
\end{tabular}

\section{A. Alimentary tract and}

metabolism

Glibenclamide
Loperamide
Mebeverine
Metopimazine
Miconazole
Ornithine oxoglurate
Porcine pancreatin
Saccharomyces Boulardii
Sitagliptin
Trimebutine
C. Cardiovascular system
Bisoprolol + hydrochlorothiazide
Spironolactone + furosemide
Dermatologicals
Dexpanthenol
Retinol

J. Antiinfectives for systemic use

Fosfomycin

Spiramycin + metronidazole

M. Musculo-skeletal system

Diclofenac

Ibuprofen

N. Nervous system

$\begin{array}{ll}\text { Acetylleucine } & 3,02[2,72 ; 3,32] \\ \text { Betahistine } & 2,96[2,66 ; 3,26] \\ \text { Clonazepam } & 3,21[2,91 ; 3,52] \\ \text { Duloxetine } & 2,76[2,51 ; 3,02] \\ \text { Fluoxetine } & 3,18[2,93 ; 3,43] \\ \text { Haloperidol } & 2,88[2,60 ; 3,16] \\ \text { Hydroxyzine } & 3,08[2,75 ; 3,40] \\ \text { Lorazepam } & 3,13[2,82 ; 3,44] \\ \text { Lysine acetylsalicylate } & 3,24[2,95 ; 3,53] \\ \text { Milnacipran } & 2,96[2,70 ; 3,21] \\ \text { Tianeptine } & 3,24[2,97 ; 3,50] \\ \text { Tramadol } & 2,94[2,67 ; 3,20] \\ \text { Tramadol + acetaminophen } & 3,14[2,86 ; 3,41]\end{array}$

S. Sensory organs

Dexamethasone + neomycin + polymyxin B
$3,38[2,98 ; 3,60]$

$3,17[2,88 ; 3,46]$
$3,12[2,82 ; 3,41]$
$3,15[2,89 ; 3,41]$
$3,10[2,84 ; 3,36]$
$3,13[2,85 ; 3,42]$
$3,31[2,99 ; 3,64]$
$3,18[2,97 ; 3,39]$
$2,81[2,50 ; 3,12]$
$3,17[2,91 ; 3,44]$
$2,96[2,70 ; 3,23]$

$3,12[2,88 ; 3,35]$

$2,94[2,67 ; 3,21]$

$3,08[2,77 ; 3,39]$

$3,02[2,78 ; 3,26]$

$3,33[2,98 ; 3,67]$

$3,38[2,52 ; 3,06]$

$3,02[2,70 ; 3,34]$

$3,02[2,72 ; 3,32]$

$2,96[2,66 ; 3,26]$

$3,21[2,91 ; 3,52]$

, $1 ; 3,02]$

$2,88[2,60 ; 3,16]$

$3,13[2,82 \cdot 3,44]$

$3,24[2,95 ; 3,53]$

$2,96[2,70 ; 3,21]$

$2,94[2,67 ; 3,20]$

$3,14[2,86 ; 3,41]$

$2,90[2,62 ; 3,18]$

*ATC: Anatomic, Therapeutic and Chemical classification.

molecules validated by the experts through the Delphi process and considered as PIM by the literature. Of the 30 molecules present in the PDE list, 7 of them were considered as potentially inappropriate only beyond a certain daily dose; 8 could be used with caution in view of the literature and one was proposed in the form of eye drops and not for systemic use.

On the other hand, during the Delphi process, the experts identified 31 additional molecules as potentially inappropriate in the elderly and there has been no prior mention of these in the literature (see Table 4).

\subsection{Generation of the final PDE list}

As mentioned above, the PDE list contains 252 drugs. A version of the list is shown in Table 5. To improve the effective use of the PDE list, valuable information for daily practices were added [the list with specific information concerning each drug is available at $h t t p: / / w w w$.ars.alsace. sante.fr/Liste-preferentielle-de-medica.144691.0.html (language: French)]. These data were intended to guide the physician in his prescription and the nurses in drug administration. For each molecule, the existence of generic drugs was specified, all dosages were mentioned, galenic forms commonly encountered were listed (tablets, capsules, oral solutions ...). For dry oral forms, the possibility of crushing the tablets or opening the capsules was described. The shelf life of oral liquid forms after first opening the container was indicated. Sugar content, sodium, potassium and ethanol were also indicated. For the 30 drugs in the PDE list considered as potentially inappropriate for the elderly by the literature, all the criteria developed in the reviews were reproduced and put forth such as arguments, clinical monitoring, therapeutic alternatives.... Warnings were indicated when the state of renal or hepatic functions needed to be taken into account for prescription.

\section{Discussion}

We have proposed a preferential list of drugs adapted to the elderly in nursing homes (PDE list) that includes molecules and their presentation forms having a utility, a favorable balance risk/benefit or a well-established use in this particular population. This list is based upon methods that included : i) creating a preliminary list from drug formularies used in daily practices in nursing homes in Alsace, ii) soliciting experts through a Delphi process, iii) identifying molecules considered in literature as PIM. Thus, the PDE list is the result of multifaceted interventions to achieve optimal results for prescribing drugs for elderly people.

The field for optimization of drug prescriptions in the elderly has received great attention in the last few years. A range of strategies has been implemented to precisely define inappropriate practices in older people 
Table 3 Drugs considered as appropriate in the elderly by the experts but inappropriate according to the literature

\begin{tabular}{cc}
\hline ATC* classification system & $\begin{array}{c}\text { Drug evaluation on the 5-point } \\
\text { Likert scale mean and } 95 \% \\
\text { confidence interval }\end{array}$
\end{tabular}

\section{A. Alimentary tract and}

metabolism

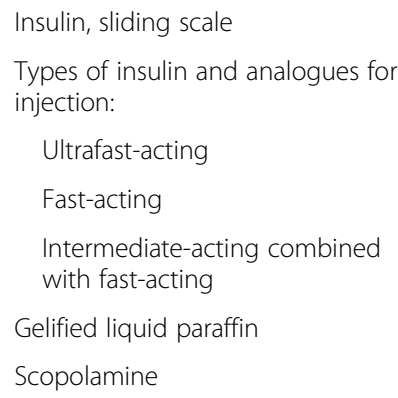

\section{Cardiovascular system}

Amiodarone

Digoxin (doses $>0,125 \mathrm{mg} / \mathrm{d}$ or [c]ser $>1.2 \mathrm{ng} / \mathrm{ml}$ )

Nicardipine

Sotalol

$1,59[1,33 ; 1,85]$

$1,60[1,35 ; 1,84]$

$1,62[1,36 ; 1,88]$

$2,39[2,01 ; 2,77]$

$2,39[2,01 ; 2,77]$

$1,41[1,23 ; 1,59]$

$1,81[1,52 ; 2,10]$

$2,10[1,74 ; 2,46]$

$2,18[1,85 ; 2,52]$

$2,26[1,99 ; 2,52]$

Spironolactone (doses $>25 \mathrm{mg} / \mathrm{d}$ )

J. Anti-infectives for systemic use Nitrofurantoin

M. Musculo-skeletal system

Tiemonium

$2,20[1,82 ; 2,57]$

N. Nervous system

Alprazolam (doses > $2 \mathrm{mg} / \mathrm{d}$ )
Carbamazepine
Citalopram
Clozapine
Escitalopram
Loxapine
Mirtazapine
Olanzapine (doses > $10 \mathrm{mg}$ )
Oxazepam (doses > $60 \mathrm{mg} / \mathrm{d}$ )
Paroxetine
Piribedil
Risperidone
Sertraline
Venlafaxine
Zolpidem (doses $>5$ mg/d)
Zopiclone (doses $>3,5 \mathrm{mg} / \mathrm{d}$ )

$2,10[1,81 ; 2,40]$

$2,51[2,18 ; 2,84]$

$1,96[1,71 ; 2,20]$

$2,38[2,04 ; 2,71]$

$1,92[1,67 ; 2,17]$

$2,64[2,31 ; 2,96]$

$2,50[2,17 ; 2,82]$

$2,23[1,89 ; 2,56]$

$2,04[1,74 ; 2,34]$

$1,89[1,67 ; 2,11]$

$2,63[2,28 ; 2,96]$

$1,98[1,73 ; 2,23]$

$2,11[1,85 ; 2,37]$

$2,27[1,97 ; 2,57]$

$2,35[2,06 ; 2,65]$

$2,32[2,00 ; 2,63]$
Table 3 Drugs considered as appropriate in the elderly by the experts but inappropriate according to the literature (Continued)

S. Sensory organs

Indomethacin (if oral route) $2,13[1,89 ; 2,37]$

*ATC: Anatomic, Therapeutic and Chemical classification.

(Topinkova et al. 2012). For example, efforts have been made in the USA, in Germany and in France to identify PIMs among drugs that are available in each of these countries (The American Geriatrics Society 2012 Beers Criteria Update Expert P 2012; Holt et al. 2010; Laroche et al. 2007) in order to be used with caution. The best known screening tool to reduce inappropriate prescribing is the Beers list which has been recently updated by the American geriatrics society (The American Geriatrics Society 2012 Beers Criteria Update Expert P 2012). These lists can also be called "negative lists". By contrast, the issue of appropriate medication per $s e$ is poorly documented. The use of lists containing drugs with a benefit-to-risk ratio acceptable in the elderly is rarely proposed as an approach that can be used to ensure the appropriateness of prescribing, and as far as we know, our PDE list constitutes the first data ever published in France.

The methodology used for building the PDE list began with an inventory of the available drug formularies used in nursing homes in Alsace. Eleven drug formularies were analyzed, 591 drugs were counted. The comparison of the content of these formularies and the data obtained from Alsatian general health insurance concerning reimbursed drugs for the elderly authorized us to state that these 591 drugs were representative of those used in the whole region.

For practical reasons, all the molecules were not reviewed by experts. If the drug was present in $20 \%$ of the analyzed formularies- $20 \%$ thus being set as the arbitrary cut-off percentage- it was then included to be part of the preliminary list. The main argument for the determination of the deciding percentage was based on the idea that a molecule present in only one or two formularies responded to needs associated with specific care management.

The Delphi method is a consensus technique used and validated in various health domains such as various clinical practices (Jones \& Hunter 1995). This approach allowed us to submit the preliminary list to a panel of experts. The subjectivity of the assessment by a consensus of experts is obvious, but can be overcome by requesting a large number of experts. In our case, 48 experts participated in the first round of questioning, and 53 completed the second round. Moreover, the PDE list combined this data with the opinion of practitioners 
Table 4 Drugs considered as inappropriate in the elderly by the experts but appropriate according to the literature ATC: Anatomic, Therapeutic and Chemical classification Drug evaluation on the 5-point Likert scale Mean and 95\% confidence interval

A. Alimentary tract and metabolism

First round

Second round

Acarbose

Anethole trithione

Glimepiride

Magnesium aspartate

Magnesium carbonate

Magnesium lactate + pyridoxine

Nifuroxazide

Ranitidine

Ursodeoxycholic acid

\section{B. Blood and blood forming organs}

Tranexamic acid

\section{Cardiovascular system}

Cibenzoline

Diosmin

Fenofibrate

Trimetazidine

\section{Dermatologicals}

Terbinafine

G. Genito-urinary system and sex hormones

Neomycin + nystatin + metronidazole

\section{H. Systemic hormonal preparations}

Salmon calcitonin

\section{J. Anti-infectives for systemic use}

Telithromycin

\section{Musculo-skeletal system}

Celecoxib
Chondroitin sulfate
Dantrolene
Strontium ranelate
Thiocolchicoside
Avocado and soybean oil

\section{N. Nervous system}

Acetaminophen + caffeine + opium

Buprenorphine

Pipamperone

Selegiline

Tropatepine

\section{R. Respiratory system}

Prednisolone + naphazoline

Theophylline

$$
\begin{aligned}
& 2,97[2,64 ; 3,31] \\
& 2,88[2,55 ; 3,21] \\
& 2,85[2,52 ; 3,17] \\
& 3,04[2,69 ; 3,39] \\
& 3,02[2,66 ; 3,37] \\
& 3,23[2,90 ; 3,57] \\
& 3,43[3,12 ; 3,74] \\
& 2,93[2,60 ; 3,26] \\
& 2,85[2,48 ; 3,21]
\end{aligned}
$$

$2,82[2,47 ; 3,18]$

$2,97[2,65 ; 3,30]$

$3,78[3,41 ; 4,16]$

$3,06[2,75 ; 3,38]$

$3,80[3,45 ; 4,16]$

$2,71[2,33 ; 3,08]$

$3,24[2,92 ; 3,56]$

$3,13[2,79 ; 3,49]$

$2,92[2,61 ; 3,22]$

Second round

Second round

second round

Second round

Second round

Second round

Excluded

Second round

second round

Second round

Second round

Excluded

Second round

Excluded

Second round

$3,34[3,08 ; 3,6]$

Excluded

Second round

Second round

Second round

$3,52[3,28 ; 3,77]$

Excluded

$3,82[3,51 ; 4,14]$

$3,28[2,91 ; 3,65]$

$3,23[2,90 ; 3,65]$

$3,35[2,98 ; 3,72]$

$3,15[2,78 ; 3,51]$

$3,46[3,08 ; 3,85]$

$3,06[2,74 ; 3,39]$

$3,21[2,90 ; 3,52]$

$3,48[3,15 ; 3,80]$

$3,07[2,74 ; 3,39]$

$3,32[2,95 ; 3,69]$

$3,44[3,11 ; 3,77]$

$3,41[3,06 ; 3,77]$

$3,27[3,02 ; 3,52]$

$3,33[3,07 ; 3,58]$

Excluded

$3,68[3,42 ; 3,94]$

$3,59[3,31 ; 3,87]$

$3,72[3,47 ; 3,97]$

$3,38[3,12 ; 3,64]$

Excluded

Excluded

Excluded

Excluded

Excluded

$3,47[3,2 ; 3,74]$

Excluded

$3,47[3,2 ; 3,74] \quad$ Excluded

Excluded

Second round

$3,88[3,60 ; 4,10]$

Excluded

Second round

$3,36[3,11 ; 3,62]$

Excluded

Second round

$3,82[3,55 ; 4,09]$

Excluded

Second round

$3,38[3,10 ; 3,67]$

Excluded

Excluded

Second round

$3,32[3,04 ; 3,59]$

Excluded

Second round

$3,38[3,39 ; 3,94]$

Excluded

Second round

$3,49[3,26 ; 3,71]$

Excluded

Second round

$3,62[3,34 ; 3,90]$

Excluded

Excluded

Excluded
$3,28[3,01 ; 3,57]$ 
Table 5 Medication in the elderly: the preferential list of drugs obtained by consensus from a panel of $\mathbf{5 3}$ experts (Delphi process)

\begin{tabular}{|c|c|c|c|}
\hline \multirow{2}{*}{$\begin{array}{l}\text { A. Alimentary tract and metabolism } \\
\text { Ascorbic acid }\end{array}$} & \multirow{2}{*}{$\begin{array}{l}\text { B. Blood and blood } \\
\text { forming organs } \\
\text { Acenocoumarol }\end{array}$} & \multicolumn{2}{|l|}{ C. Cardiovascular system } \\
\hline & & Acebutolol & Nicorandil \\
\hline Calcium carbonate & Acetylsalicylic acid & Amiodarone & Perindopril \\
\hline Calcium carbonate + colecalciferol & Calcium heparin & Amlodipine & Perindopril + indapamide \\
\hline Chlorhexidine + chlorobutanol & Clopidogrel & Atenolol & Pravastatin \\
\hline Colecalciferol & Cyanocobalamin & Atorvastatin & Propranolol \\
\hline Diosmectite & Enoxaparin & Benazepril + hydrochlorothiazide & Ramipril \\
\hline Domperidone & Ferrous fumarate & Bisoprolol & Rosuvastatin \\
\hline Ergocalciferol & Ferrous sulfate & Bumetanide & Simvastatin \\
\hline Esomeprazole & Ferrous sulphate + folic acid & Candesartan & Sotalol \\
\hline Gliclazide & Fluidione & Carvedilol & Spironolactone \\
\hline Insulins: ultra-fast acting, & Folic acid & Celiprolol & Spironolactone + altizide \\
\hline \multicolumn{4}{|l|}{ fast-acting, } \\
\hline \multicolumn{4}{|l|}{$\begin{array}{l}\text { intermediate - acting intermediate-acting } \\
\text { combined with fast-acting, long -acting }\end{array}$} \\
\hline Lactulose & Fondaparinux & Cicletanine & Valsartan \\
\hline Lanzoprazole & Phytomenadione & Digoxin & Valsartan + hydrochlorothiazide \\
\hline Liquid paraffin & Tinzaparin & Diltiazem & Verapamil \\
\hline Macrogol & Warfarin & Enalapril & $\begin{array}{l}\text { Zinc oxide }+ \text { titanium dioxide }+ \\
\text { carrageenane }\end{array}$ \\
\hline $\begin{array}{l}\text { Macrogol in combination with } \\
\text { potassium chloride, sodium chloride } \\
\text { and sodium bicarbonate }\end{array}$ & & Furosemide & $\begin{array}{l}\text { Zinc oxide }+ \text { titanium dioxide }+ \\
\text { carrageenane }+ \text { lidocaine }\end{array}$ \\
\hline Metformin & & Glyceryl nitrate (oral) & \\
\hline Omeprazole & & $\begin{array}{l}\text { Glyceryl nitrate (transdermal } \\
\text { patches) }\end{array}$ & \\
\hline Pancreatin & & Hydrochlorothiazide & \\
\hline Pantoprazole & & Indapamide & \\
\hline Phloroglucinol & & Irbesartan & \\
\hline Potassium chloride & & Isosorbide dinitrate & \\
\hline Psylla & & Isosorbide mononitrate & \\
\hline Racecadotril & & Lercanidipine & \\
\hline Repaglinide & & Lisinopril & \\
\hline A. Alimentary tract and metabolism & & C. Cardiovascular system & \\
\hline Scopolamine & & Lisinopril + hydrochlorothiazide & \\
\hline Sodium bicarbonate + alginic acid & & Losartan & \\
\hline Sodium bicarbonate + potassium bitartrate & & Metoprolol & \\
\hline Potassium gluconate & & Molsidomine & \\
\hline Sodium phosphate & & Nebivolol & \\
\hline Sorbitol & & Nicardipine & \\
\hline
\end{tabular}

Sterculia

D. Dermatologicals

Aciclovir

Amorolfine

\section{Dermatologicals}

Fusidic acid

Galen's wax
G. Genito-urinary system and sex hormones

Alfuzosin

Cyproterone
H. Systemic hormonal preparations

Betamethasone

Carbimazole 
Table 5 Medication in the elderly: the preferential list of drugs obtained by consensus from a panel of $\mathbf{5 3}$ experts (Delphi process) (Continued)

Betamethasone
Betamethasone + salicylic acid
Bifonazole
Calcipotriol
Calcipotriol + betamethasone
Chlorhexidine + benzalkonium
chloride + benzylic alcohol
Ciclopirox
Clobetasol
Desonide
Econazole

J. Anti-infectives for systemic use

Aciclovir
Amoxicillin
Amoxicillin + clavulanic acid
Amphotericin B
Azithromycin

J. Anti-infectives for systemic use

\begin{tabular}{ll} 
& systemic use \\
\hline Cefixime & Norfloxacin \\
Ceftriaxone & Ofloxacin \\
Cefuroxim & Oseltamivir \\
Ciprofloxacin & Pristinamycin \\
Clarithromycin & Roxithromycin \\
CloxacillinDoxycycline & Spiramycin \\
& Sulfamethoxazole + \\
& trimethoprim \\
& Valaciclovir
\end{tabular}

\section{N. Nervous system}

Acetaminophen

Alprazolam

Carbamazepine

Citalopram

\section{Clozapine}

Codeine + acetaminophen

Donepezil

Entacapone

Escitalopram

Fentanyl

Gabapentin

Galantamine

Hydrochloride morphine

Glycerol + vaseline + liquid
paraffin
Hydrocortisone
Ketoconazole
Povidone-iodine
Sodium hypochlorite
Triethanolamine
Vaseline
Zinc oxide
Zinc oxide + fish liver oil
Zinc oxide + glycerol + talcum
powder

J. Anti-infectives for systemic use

L. Antineoplastic and immunomodulating agents

Fluconazole

Fusidic acid

Levofloxacin

Metronidazole

Nitrofurantoin

Anastrozole

Bicalutamide

Letrozole

Leuprorelin

Tamoxifen
Tamsulosin

Trospium
Glucagon

Hydrocortisone

Levothyroxine sodium

Methylprednisolone

Prednisolone

Prednisone

\section{Musculo-skeletal system} Alendronic acid

Alendronic acid + colecalciferol

Allopurinol

Clodronic acid

Colchicine + tiemonium + opium

M. Musculo-skeletal system Diclofenac (topic use)

Diclofenac (oral use)

Ibuprofen

Risedronic acid

\section{N. Nervous system}

Mirtazapine

Nefopam

Olanzapine

Oxazepam

Paroxetine

Piribedil

Pramipexole

Pregabalin

Risperidone

Rivastigmine

Ropinirole

Sertraline

Fast -acting Morphine sulfate
R. Respiratory system

$\begin{array}{ll}\text { Acetylcysteine } & \text { Acetazolamide } \\ \text { Beclometasone } & \text { Artificial tears } \\ \text { Budesonide } & \text { Carbomers } \\ \text { Carbocisteine } & \text { Dexamethason } \\ \text { Oxytetracycline } & \text { Indometacin } \\ \text { Desloratadine } & \text { Latanoprost } \\ \text { Fenoterol + ipratropium } & \text { Ofloxacin } \\ \text { Formoterol } & \text { Pilocarpine } \\ \text { Helicidine } & \text { Retinol } \\ \text { Ipratropium bromide } & \text { Rifamycin } \\ \text { Levocetirizine } & \text { Timolol } \\ \text { Loratadine } & \text { Xylene } \\ \text { Montelukast } & \end{array}$

Salbutamol

\section{S. Sensory organs}

Acetazolamide
Artificial tears
Carbomers
Dexamethasone +
oxytetracycline
Indometacin
Latanoprost
Ofloxacin
Pilocarpine
Retinol
Rifamycin
Timolol
Xylene


Table 5 Medication in the elderly: the preferential list of drugs obtained by consensus from a panel of $\mathbf{5 3}$ experts (Delphi process) (Continued)

\begin{tabular}{lll}
\hline Lamotrigine & Long-actingMorphine sulfate & Salmeterol + fluticasone \\
Levodopa + decarboxylase inhibitor & Tiapride & Terbutaline \\
$\begin{array}{ll}\text { Levodopa + decarboxylase inhibitor +COMT } \\
\text { inhibitor }\end{array}$ & Tramadol + acetaminophen & Tiotropium bromide \\
Lidocaine & Valproic acid & Tixocortol \\
Lidocaine + prilocaine & Valpromide & \\
Lithium & Venlafaxine & \\
Loxapine & Zolpidem & \\
Memantine & Zopiclone & \\
Mianserin & &
\end{tabular}

The detailed list is available at http://www.ars.alsace.sante.fr/Liste-preferentielle-de-medica.144691.0.html (language: French); presentation of drugs according to ATC: Anatomic, Therapeutic and Chemical classification.

commonly involved in the management of drugs given to elderly patients. These experts represented different specialties and were from different parts of France and Europe, in order to give a large overview of the practices. Finally, experts were consulted separately, hence they were not able to discuss together but were capable of adding commentaries in order to communicate their ideas between both rounds. This approach allowed experts to express their opinions independently and confidentially without any peer-pressure or conflicts of judgement that may occur during a face-to-face meeting. Therefore, we are confident that drugs listed here, are definitely regarded as useful in daily practices by a large and diverse group of specialists.

In our study, 30 drugs from the PDE list were considered as potentially inappropriate in view of the published studies (The American Geriatrics Society 2012 Beers Criteria Update Expert P 2012; Holt et al. 2010; Laroche et al. 2007). We however decided to keep these drugs in the PDE list and decided to clearly identify them as potentially inappropriate as a reminder for closer monitoring of these 30 drugs. On the other hand, experts in our study excluded 31 molecules which are not cited in the literature as inappropriate. Some of them have restricted indications or seem to be unnecessary in nursing homes: tranexamic acid, calcitonin, dantrolene, ursodeoxycholic acid, cibenzoline are examples. Others present a lack of interest: avocado and soybean oil, chondroitin sulfate, magnesium. Finally, some molecules present an unfavorable benefit-to-risk ratio: terbinafine, theophylline, ranitidine, strontium ranelate and acarbose. The differences between the published PIM lists and our results could reflect the use of different methodological approaches, the subjectivity of assessments obtained by consensus among experts, the pharmaceutical supply available in different countries. It should also be noted that significant differences exist between the PIM lists published so far (The American Geriatrics Society 2012
Beers Criteria Update Expert P 2012; Holt et al. 2010; Laroche et al. 2007).

Concerning the administration of drugs in the elderly, as mentioned by Caussin et al. (Caussin et al. 2012), there is an enormous potential for improvement in drugs safety and effectiveness. In geriatrics, it is frequent to crush pills or simply open capsules so that patients presenting problems swallowing and/or behavior issues may take the medicines more easily. In the study mentioned above, $42 \%$ of crushed drugs had a galenic presentation which did not allow crushing. These practices, marked by frequent errors, may significantly alter the effectiveness of drugs, their pharmacokinetics and even could lead to toxic effects for both patients and caregivers. All classes of drugs are concerned. To avoid these potential iatrogenic and professional risks, the PDE list indicates clearly which drugs should not be crushed and, in those cases, suggests alternative measures.

Finally, the PDE list constitutes a general guide for the optimization of both prescription and administration of drugs in nursing homes and this could help reduce misuses and poly-medication, both of which are constant preoccupations to avoid ADRs.

Nevertheless, this PDE list has some limitations. First of all, it is important to concede that the PDE list was built from Alsatian data. However, physicians from other French regions should not encounter any major problems adopting this tool in their nursing homes. Solicited experts belong to national professionals and scientific societies, some of them coming from different other regions of France. This guaranteed that local prescribing practices did not overly influence the development of the list. On the other hand, the PDE list has limited applicability for international use. Country-specific prescribing trends, disease epidemiology, differences in drug availability must not be ignored.

Secondly, the PDE list is focused on medication in nursing homes. The extension of the study to elderly in 
ambulatory care could be viewed as one of the next important steps in the updating of the PDE list.

Thirdly, this PDE list should not be used without adequate clinical expertise. For a given patient, a benefitto-risk ratio for each drug has to be assessed considering clinical conditions, comorbidities, functional status, other drugs taken and prognosis. Further, the issue of prescribing appropriateness, in its broader sense, must encompass steps in favor of non-drug approaches (beneficial drug omission) and include also patients' preferences to achieve optimal results (Spinewine et al. 2007).

Fourthly, the PDE list could be controversial because of the limitations imposed by this list to the prescribing physician. It can be argued that the PDE list is a starting tool. Specific adaptations conducted within each nursing home in collaboration with physicians, pharmacist, nurses, and possibly administrative directors, are a suitable response to allow the intelligent and judicious adoption of the PDE list.

\section{Conclusion}

Establishing a list of drugs to be used preferentially in nursing homes is written in the French Code of Public Health (articles L. 313-12 and L. 5126-6-1). It has to be developed in each nursing home in a multidisciplinary context by including coordinating physician, pharmacist and general practitioners. As we can see in this article only few Alsatian nursing homes have developed their own formularies.

The PDE list constitutes a unique and starting guideline and can by no means be enforced by law but it can be used mostly to harmonize practices in nursing homes and to help physicians and nurses to achieve best possible care management. We expect that the PDE list will have to be regularly reviewed to be fully useful to health professionals. A further challenge to facilitate the adoption of the PDE list will be to demonstrate that implementation of this tool, adjusted to the needs of nursing homes, will result in objective and quantifiable improvements in the management of older people. We are currently completing a randomized controlled study among 10 nursing homes in Alsace to assess these issues in terms of clinical and economic outcomes.

\section{Competing interests}

All authors declare: that there has been no support from any organization for the submitted work; and no financial relationships with any organizations that might have an interest in the submitted work; and further no other relationships or activities that could appear to have influenced the submitted work.

\section{Authors' contribution}

MCR and BM were responsible for the conception of the study. SH and AR conducted the study and interpreted the data analyses. BM drafted the article and $\mathrm{SH}, \mathrm{AR}, \mathrm{MCRV}$ revised the manuscript. All authors read and approved the final manuscript.

\section{Acknowledgements}

We thank the experts who participated in the study, namely: Marie AUBE (Pharmacist, France); Pr. Jean Pierre BAEYENS (Geriatrician, Belgium), Lionel BENDAVID (General practitioner, coordinating physician, France); Dr. Benoît BERGAENTZLE (Pharmacist, France); Dr. Anne-Marie BOSSERT (Pharmacist, France); Pr. Christophe BULA (Geriatrician, Swiss); Dr. William CALLET (Geriatrician, France); Dr. Karen CAYRON (General practitioner, coordinating physician, France); Dr. Philippe CLAUDE (Geriatrician, France); Dr. Félix COHEN (General practitioner, coordinating physician, France); Drs. Jean-Philippe DANIEL et Bénédicte GOURIEUX (Pharmacist, France); Drs. Eva DELAGO et María MUÑOZ GARCIA (Pharmacists, Spain); Dr. Mohamed El AATMANI (Pharmacist, France); Dr. Gabrielle DE GUIO (Geriatrician, France); Dr. Daniel GUILLARD (Pharmacist, France); Dr. Francoise GUILLARD (Pharmacist, France); Dr. Alain HEITZ (Geriatrician, France); Pr. Christiane HEITZ (Pharmacist, France); Dr. Maurice HERTZOG (Geriatrician, France); Dr. Roselyne ILTIS (Geriatrician, France); Pr. Jean-Louis IMBS (Pharmacologist, France); Pr. Georges KALTENBACH (Geriatrician, France); Dr. Patrick KARCHER (Geriatrician, France); Dr. Franck KESSLER (Pharmacist, France); Dr. Nhôn LAM (Pharmacist, France); Dr. Dominique LANG (Geriatrician, France); Dr. Pierre-Olivier LANG (Geriatrician, Swiss); Dr. Anne LEVASSEUR-GOETZ (General practitioner, coordinating physician, France); Dr. Michel LEVEQUE (Geriatrician, France); Dr. Alain LION (Geriatrician, France); Dr. Catherine LUTTRINGER (Pharmacist, France); Dr. Joëlle MARCHAL-FENNINGER (Geriatrician, France); Dr. Pascal MEYVAERT (Geriatrician, France); Dr. Jean-Marc MICHEL (Geriatrician, France); Dr. Caroline OULERICH (General practitioner, coordinating physician, France); Dr. Yves PASSADORI (Geriatrician, France); Dr. Laurent PERELLO (Pharmacist, France); Drs. Michel PIMBEL et Julien DELEDIQUE (Pharmacists, France); Dr. Max PRUDENT (Geriatrician, France); Dr. Marcel RUETSCH (Geriatrician, France); Dr. Thierry SCHERER (General practitioner, coordinating physician, France); Dr. Pierre-Paul SCHLEGEL (General practitioner); Dr. Alexandre SIMALEU (General practitioner, coordinating physician, France); Dr. Martine STEFFEN (Geriatrician, France); Dr. Martine TEBACHER (pharmacovigilant, France); Dr. Jean-Marc TOSI (Pharmacist, France); Dr. Philippe TURNANI (Pharmacist, France); Pr. Jean-Marie VETEL (Geriatrician, France); Pr. Thomas VOGEL (Geriatrician, France); Dr. Luc WALTER (General practitioner, coordinating physician, France); Dr. Marie WELSCH (pharmacovigilant, France); Dr. Claude WINDSTEIN (Pharmacist, France); Dr. Martine ZEISSER (General practitioner, coordinating physician, France).

\section{Author details}

1OMEDIT d'Alsace, Cité administrative Gaujot, 14, rue du Maréchal-Juin, F-67084 Strasbourg, France. ${ }^{2}$ Service de Pharmacie, Centre Hospitalier Universitaire Vaudois, 46, rue du Bugnon, CH-1011 Lausanne, Switzerland. ${ }^{3}$ Service de Pharmacie, Hôpitaux Universitaires de Strasbourg, Université de Strasbourg, Faculté de Pharmacie, Laboratoire HuManiS (EA 7308), 1, avenue Molière, BP 83 049, Strasbourg, Cedex F-67098, France.

Received: 9 April 2014 Accepted: 1 August 2014

Published: 7 August 2014

\section{References}

ANSM (ex Afssaps) (2005) Prévenir la latrogénèse Médicamenteuse chez le sujet âgé. [cited 2014 Feb]. Available from http://www.cnsa.fr/IMG/pdf/iatogenie_ medicamenteuse.pdf

Beijer HJ, de Blaey CJ (2002) Hospitalisations caused by adverse drug reactions (ADR): a meta-analysis of observational studies. Pharm World Sci: PWS 24(2):46-54

Caussin ML, Mourier W, Philippe S, Capet C, Adam M, Reynero N, Jouini C, Colombier AS, Kadri K, Landrin I, Gréboval E, Rémy E, Marc F, Touflet M, Wirotius F, Delabre N, Le Hiress C, Rorteau V, Vimard M, Dufour M, Tharasse C, Dieu B, Varin R, Doucet J (2012) Crushing drugs in geriatric units: an "handicraft" practice with frequent errors which imposed recommendations. Rev Med Interne 33(10):546-551

Chen YC, Fan JS, Chen MH, Hsu TF, Huang HH, Cheng KW, Yen DH, Huang Cl, Chen LK, Yang CC (2014) Risk factors associated with adverse drug events among older adults in emergency department. Eur J Intern Med 25(1):49-55

Dalkey NC (1969) An Experimental Study of Group Opinion, Santa Monica. RAND Corporation, RM-5888-PR, California, [cited 2014 Feb]. Available from http://www.rand.org/pubs/research_memoranda/RM5888

French data bases « Thériaque » (2014). Available from: http://www.theriaque. org/apps/recherche/rch_simple.php

Holt S, Schmiedl S, Thurmann PA (2010) Potentially inappropriate medications in the elderly: the PRISCUS list. Dtsch Arztebl Int 107(31-32):543-551 
Jones J, Hunter D (1995) Consensus methods for medical and health services research. BMJ 311(7001):376-380

Laroche ML, Charmes JP, Merle L (2007) Potentially inappropriate medications in the elderly: a French consensus panel list. Eur J Clin Pharmacol 63(8):72-731, Aug

Leendertse AJ, Egberts AC, Stoker LJ, van den Bemt PM, Group HS (2008) Frequency of and risk factors for preventable medication-related hospital admissions in the Netherlands. Arch Intern Med 168(17):1890-1896

Maher RL, Hanlon J, Hajjar ER (2014) Clinical consequences of polypharmacy in elderly. Expert Opin Drug Saf 13(1):57-65, Jan

Matell MS, Jacoby J (1971) Is there an optimal number of alternatives for Likert scale items? Study I: Reliability and validity. Educ Psychiol Measure 31:657-674

OMEDIT Haute-Normandie (2014). Available from: http://www.omedit-hautenormandie.fr/

Petrovic M, van der Cammen T, Onder G (2012) Adverse drug reactions in older people: detection and prevention. Drug Aging 29(6):453-462

Spinewine A, Schmader KE, Barber N, Hughes C, Lapane KL, Swine C, Hanlon JT (2007) Appropriate prescribing in elderly people: how well can it be measured and optimised? Lancet 370(9582):173-184

The American Geriatrics Society 2012 Beers Criteria Update Expert P (2012) American Geriatrics Society updated Beers criteria for potentially inappropriate medication use in older adults. J Am Geriatr Soc 60(4):616-631

Topinkova E, Baeyens JP, Michel JP, Lang PO (2012) Evidence-based strategies for the optimization of pharmacotherapy in older people. Drug Aging 29(6):477-494

doi:10.1186/2193-1801-3-413

Cite this article as: Hannou et al: Medication in nursing homes in Alsace: a preferential list of drugs obtained by consensus. SpringerPlus 2014 3:413

\section{Submit your manuscript to a SpringerOpen ${ }^{\circ}$} journal and benefit from:

- Convenient online submission

- Rigorous peer review

- Immediate publication on acceptance

- Open access: articles freely available online

- High visibility within the field

- Retaining the copyright to your article

Submit your next manuscript at $\gg$ springeropen.com 